\title{
L. The scintillations produced by radium
}

\section{Prof. R.W. Wood}

To cite this article: Prof. R.W. Wood (1905) L. The scintillations produced by radium, Philosophical Magazine Series 6, 10:58, 427-430, DOI: 10.1080/14786440509463390

To link to this article: http://dx.doi.org/10.1080/14786440509463390

$$
\text { 册 Published online: } 16 \text { Apr } 2009 .
$$

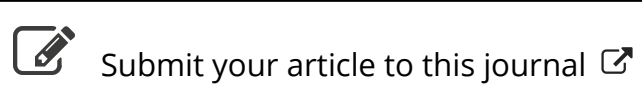

\footnotetext{
Џll Article views: 4
}

Q View related articles ¿

Citing articles: 2 View citing articles $\square$ 
or no rotatory power is exhibited for red or yellow light, though this portion of the spectrum is filled with fine absorption-lines, and the blue region is also wanting in the rotation spectrum, though the absorption is strongest at this point. These effects are at present under investigation, and will be reported in a subsequent paper.

The investigation reported in the present paper is one of a series made possible through substantial aid received from the Rumford Fund, two grants having been made by the American Academy for a study of the optical properties of sodium vapour.

Much assistance has also been rendered by $\mathrm{M}:$. A. H. Pfund, for whose services I am indebted to the Carnegie Institute.

L. The Scintillations produced by Radium. By Prof. R. W. Wood *

[Plate VI.]

THE scintillations of phosphorescent zinc sulphide, when subjected to the bombardment of the radium corpuscles, does not appear to have been satisfactorily explained up to the present time. Crookes regarded each flash as due to the impact of a positive electron or alpha particle, while Becquerel regards the production of light as a secondary effect resulting from cleavages of the crystals brought about by the action of the rays. Neither hypothesis, as it stands, seems quite convincing. I do not know whether any estimate has ever been made of the actual number of alpha particles emitted in unit time from a given amount of radium, but it certainly seems as if the number must far surpass the number of flashes of light as seen in the spinthariscope. As to the second hypothesis, the only argument advanced in support of it appears to be the circumstance that zine sulphide crystals when rubbed or crushed show similar flashes of light. This argument is not very convincing, for it amounts to saying that similar effects must result from similar causes. On the other hand, the cleavage hypothesis removes the trouble regarding the number of flashes as compared with the probable number of electrons, as well as the difficulty in the conception of an appreciable flash being produced by a single electron. The experiments described in this paper were completed just a year ago, and were undertaken in the hope of settling the question of the cause of the flash. As they did not lead to sufficiently definite conclusions to satisfy me,

\footnotetext{
* Communicated by the Author.
} 
I refrained from publishing the results, in the bope and belief that some one else would succeed in solving the question in a more conclusive manner. As no further work appears to have been done, and no more satisfactory theory bas been advanced, I have decided to publish them for what they are worth, together with the conclusion which I have drawn from them.

It was hoped that the cleavage hypothesis could be either strengthened or weakened by determining the duration of the spinthariscope flashes, and the flashes produced by cleavage. If the order of magnitude was found to be different in the two cases, it would be a very strong argument against the hypothesis of Becquerel. The duration of the flash due to the radium bombardment was determined without difficulty. The rim of a wooden disk, mounted on the shaft of a small electric motor, was coated with zine sulphide, and a speck of radium supported above it on a needle-point. The bombarded surface was viewed in a dark room with a small lens. The flashes remained sharp even when the motor was running at a pretty good rate, but on further increasing the speed they became less distinct, being drawn out into short streaks. It was pretty definitely determined that the duration of the flash was somewhere between $\frac{1}{150000}$ and $\frac{1}{20000}$ of a second.

The only method I was able to devise for determining the duration of the tribolnminescence was the simple expedient of touching the rim of the revolving disk with the point of a slender rod of glass. The glow due to the crushing of the crystals extended halfway around the disk, even when it was running at low speed. In addition to the long streak of light, there is always a bright star at the point where the rod is in contact with the sulphide surface. This is probably due to the fact that some of the luminous crystals are held back by the rod, stick to it in other words, and does not necessarily indicate that the first flash is of very brief duration. If the latter wers the case, we should expect the glowing star to be slightly drawn out at very high speeds, which is not the case. This experiment appears to indicate that the flashes due to the radium bombardment have a much shorter duration than the flashes which result from fractures of the crystals, and there seems to be no way of escaping from the conclusion that the two phenomena are not very closely related.

A photographic study of the phenomenon was then undertaken to determine the integral effect of a large number of flashes, for it seemed possible that the flashes might recur at certain points more often than at others. 
A small heap of the phosphorescent sulphide was pressed Hat with a clean piece of glass. A perfectly flat smooth surface was thus formed, free from any cement or other binding substance. A speck of radium was mounted above it, and the scintillating surface photographed with a Zeiss microscope, using a low-power objective, the magnification not exceeding 20 diameters. An exposure of three days was given, which was sufficient to yield an excellent negative. A print from the plate is reproduced in Pl. VI. fig. 1. The photograph reminds one strongly of a picture of the moon made with telescope of moderate size. There are patches of considerable size which only phosphoresce feebly, and small points which shine brightly. The speck of radium was located at the extreme edge of the field. Although the sulphide was in the form of a very fine powder, the dark areas seemed to have a considerable size, many times larger than the largest crystals. The powder was rubbed for fifteen minutes in an agate mortar and the experiment repeated. In this case the dark areas were smaller and the bright specks more conspicuous (fig. 2). Evidently certain crystals phosphoresced much more brightly than others. To get a better idea of what was going on, a glass slide was lightly dusted with the powder and placed under the microscope. Two photographs were made of the same field of view, one by illuminating; the particles with light (dark-ground illumination), and the ' ther by exposing them for three days to the ratium bombardment. The two pictures are reproduced in figs. 3 and 4. The arrows point to the same spots on the two fields. It is at once apparent that only a small percentage of the crystals become luminous under the action of the radium rays.

This may be due to the following circumstance. It is well known that large crystals do not show the scintillations to advantage. It is also a fact that the phosphorescent power of most substances is due to minute traces of impurities. The inert crystals are probably those in which the impurity causing phosphorescence is not present, or if present, is buried under the surface. This explanation of course assumes that the crystals are not homogeneous, and we may suppose that the flash of light occurs only when an electron strikes a molecule of the impurity. Some crystals may not have the necessary molecules in a position which can be reached by the electrons. It would be worth while to pick out the active crystals and photograph them in different positions, $i . e$. turning them over between the exposures. They are so small that the experiment would not bo an easy one, but doubtless those who make pictures out of diatoms would find no difficulty in accom- 
plishing the feat. The increase in the scintillating power produced by crushing the crystals may be due to the exposure of more of the molecular impurities. If any difficulty is felt regarding the action of a single electron, we can assume as well, that the continued action of the rays results in an unstable chemical change effected upon the impurity, the flash being due to the toppling over of the molecular complex into its original condition.

The fact that the flash lasts as long as $\frac{1}{20000}$ of a second seems to point to some such action, for the wave train emitted even in this brief length of time is measured in miles, and a simple vibration started by the impact of an electron could scarcely be supposed to persist for so long a time.

LI. The Specific Heat of Iron at High Temperatures. By J. A. Harker, D.Sc., Assistant at the National Physical Laboratory, Teddington*. (From the National Physical Laboratory.)

$\triangle$ LTHOUGH a knowledge of the specitic heat of iron at A high temperatures would seem to be of vital importance to the metallurgical industry, yet it would appeas that no determination of this physical constant has been made since our high-temperature thermometric scale has been rendered definite and precise by the investigations of the last fifteen years.

Probably on account of its difficulty, the work done on the subject of specific heats at high temperature's is comparatively meagre. Apart from observations dating from more than forty years ago, a careful search in the iiterature of the subject has revealed the work of only one observer, who carried his observations up to really high temperaturesPionchon, a pupil of Berthelot, who worked in Paris in 1886. His experiments were made by the usual mixing calorimeter method, but were carried out with exceptional skill and accuracy. His specimens were heated in a specially constructed gas-furnace, those such as iron, which were of a readily oxidizable character, being protected by enclosure in a thin platinum envelope. His temperatures were measured by the Violle method of calorimetric estimation, using a small ingot of platinum heated alongside the specimen. Employing the values previously determined by Violle for the specific heat of platinum, Pionchon found for the melting-

* Communicated by the Physical Society : read May 26, 1905. 
Phil. Mag. Ser. 6, Vol. 10, Pl. VI.

FIG. 1.

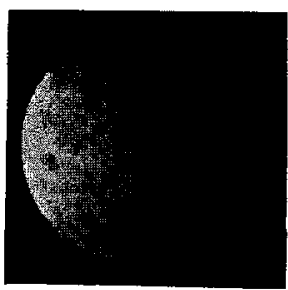

Fig. 3.

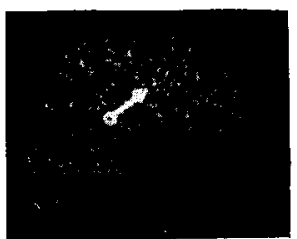

FIG. 2.

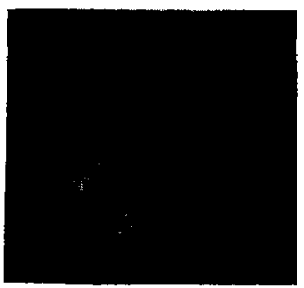

lig. 4.

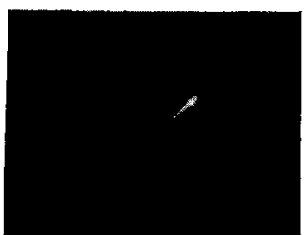

